\title{
CRACK-GEL INTERACTION ON THE STATIC AND FATIGUE FAILURE OF ASR- DAMAGED RC SLABS
}

\author{
Y. TANAKA ${ }^{*}$, Y. TAKAHASHI ${ }^{\dagger}$ AND K. MAEKAWA ${ }^{\dagger \dagger}$ \\ * IIS, The University of Tokyo \\ Tokyo, Japan \\ e-mail: yasuxi@iis.u-tokyo.ac.jp \\ ${ }^{\dagger}$ The University of Tokyo \\ Tokyo, Japan \\ e-mail: takahashi@concrete.t.u-tokyo.ac.jp \\ ${ }^{\dagger \dagger}$ The University of Tokyo \\ Tokyo, Japan \\ e-mail: maekawa@concrete.t.u-tokyo.ac.jp
}

Key words: Alkali Silica Reaction, Poro mechanics, Punching shear, Fatigue

\begin{abstract}
The research target of this study is degradation of punching shear strength due to Alkali Silica Reaction (ASR) in Reinforced Concrete (RC) slab members. At first, punching shear strength of ASR slabs was examined experimentally. The deformations of slab specimens due to ASR strongly depended on bar arrangements. Static punching shear strength also depended on bar arrangements. In addition to the static experiments, the fixed-point cyclic loadings were carried out in both dry and wet conditions. The punching shear fatigue strength of ASR-damaged specimen was reduced according to the degradation of the static punching shear capacity, but the further strength reduction was not observed even in case of the wet condition unlike normal reinforced concrete slabs. As the next step, the authors conducted the multi-scale chemo-hygral simulation with ASR-gel generations and migrations. The poromechanics-based multi-phase modeling succeeded to simulate the structural performance of ASR-damaged slabs.
\end{abstract}

\section{INTRODUCTION}

It is well known that the punching shear strength of Reinforced Concrete (RC) slabs are closely related to the mechanical properties of concrete [1]. However, little is known about the degradation effects of ASR on the punching shear strength of RC slabs. In this study, the punching shear strength of ASR slabs was examined experimentally as the first step. In addition to the static experiments, the cyclic loadings were carried out in both dry and wet conditions. As the next step, the authors conducted the multi-scale chemo-hygral simulation with ASR-gel generations and migrations to simulate deformation during the expansive reaction and the structural performance of ASR-damaged slabs.

\section{EXPERIMENTAL PROGRAM}

Eight RC slab-specimens were made with reactive aggregates while two $\mathrm{RC}$ slabspecimens were arranged with non-reactive aggregates as a reference as shown in Table 1. Table 2 shows the mix proportions of concrete. Reactivity was rooted in coarse aggregates 
Table 1: List of tested specimens

\begin{tabular}{|l|l|l|l|l|l|l|l|l|l|l|}
\hline No. ID & $\begin{array}{l}\text { ConcretNo. } \\
\text { e mix } \\
\text { Rebar } \\
\text { Layer }\end{array}$ & $\begin{array}{l}\text { Free } \\
\text { Expansion }\end{array}$ & $\begin{array}{l}\text { Load } \\
\text { type }\end{array}$ & $\begin{array}{l}\text { Wet/dry } \\
\text { condition } \\
\text { loading }\end{array}$ & $\begin{array}{l}\text { Comp. } \\
\text { strength }\end{array}$ & $\begin{array}{l}\text { Max. } \\
\text { Load }\end{array}$ & $\begin{array}{l}\text { Fatigue } \\
\text { Load }\end{array}$ & $\begin{array}{l}\text { Failure } \\
\text { cycle }\end{array}$ \\
\hline 1 & SNS & Normal & 1 & - & Static & Dry & 41 & 366 & - & - \\
\hline 2 & SAS & ASR & 1 & 6400 & Static & Dry & $24(12 *)$ & 214 & - & - \\
\hline 3 & SNF-D & ASR & 1 & - & Fatigue & Dry & 41 & - & 258 & 3039 \\
\hline 4 & SNF-W & ASR & 1 & - & Fatigue & Wet & 41 & - & 258 & 1079 \\
\hline 5 & SAF-D & ASR & 1 & 6400 & Fatigue & Dry & $24(14)$ & - & 151 & 9521 \\
\hline 6 & SAF-W & ASR & 1 & 6400 & Fatigue & Wet & $24(14)$ & - & 151 & 12870 \\
\hline 7 & DNS & Normal & 2 & - & Static & Dry & 37 & 347 & - & - \\
\hline 8 & DAS-2 & ASR & 2 & 2600 & Static & Dry & $43(30)$ & 321 & - & - \\
\hline 9 & DAS-4 & ASR & 2 & 3800 & Static & Dry & $43(31)$ & 316 & - & - \\
\hline 10 & DAS-6 & ASR & 2 & 6300 & Static & Dry & $43(24)$ & 338 & - & - \\
\hline
\end{tabular}

* Compressive strength of free expansion cylinders

Table 2: Mix proportions of concrete

\begin{tabular}{|c|c|c|c|c|c|c|c|c|c|}
\hline \multirow[b]{2}{*}{ Type } & \multirow[b]{2}{*}{$\begin{array}{l}\mathrm{G}_{\max } \\
(\%)\end{array}$} & \multirow[b]{2}{*}{$\begin{array}{l}\mathrm{W} / \mathrm{C} \\
(\%)\end{array}$} & \multirow[b]{2}{*}{$\begin{array}{l}\mathrm{s} / \mathrm{a} \\
(\%)\end{array}$} & \multicolumn{6}{|c|}{ Unit weight $\left(\mathrm{kg} / \mathrm{m}^{3}\right)$} \\
\hline & & & & W & $\mathrm{C}$ & S & G & Ad1 & $\begin{array}{l}\text { Alkali } \\
\text { content } \\
\left(\mathrm{kg} / \mathrm{m}^{3}\right)\end{array}$ \\
\hline ASR & 25 & 55 & 41.0 & 170 & 309 & 738 & 1095 & 0.77 & 9.5 \\
\hline Normal & 25 & 55 & 41.0 & 170 & 309 & 738 & 1095 & 0.77 & 0 \\
\hline
\end{tabular}

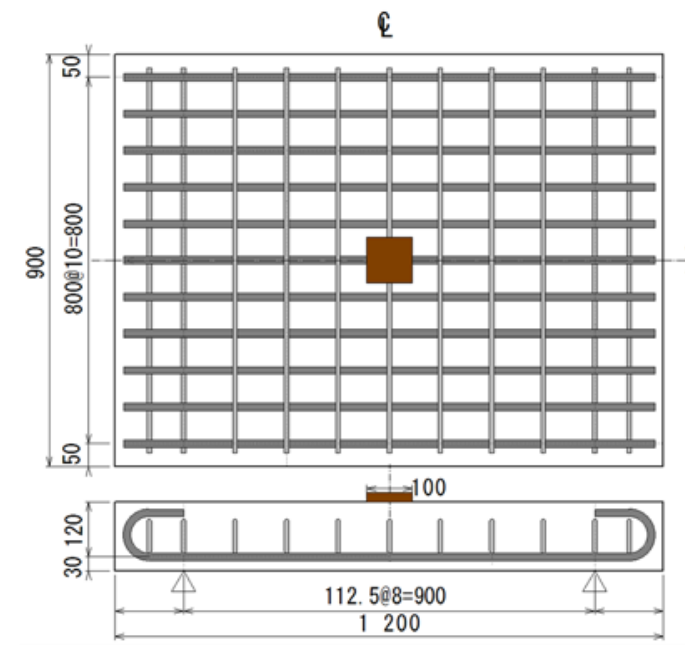

(a) No.1-6

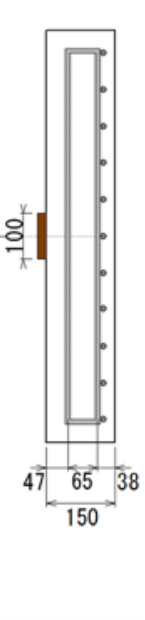

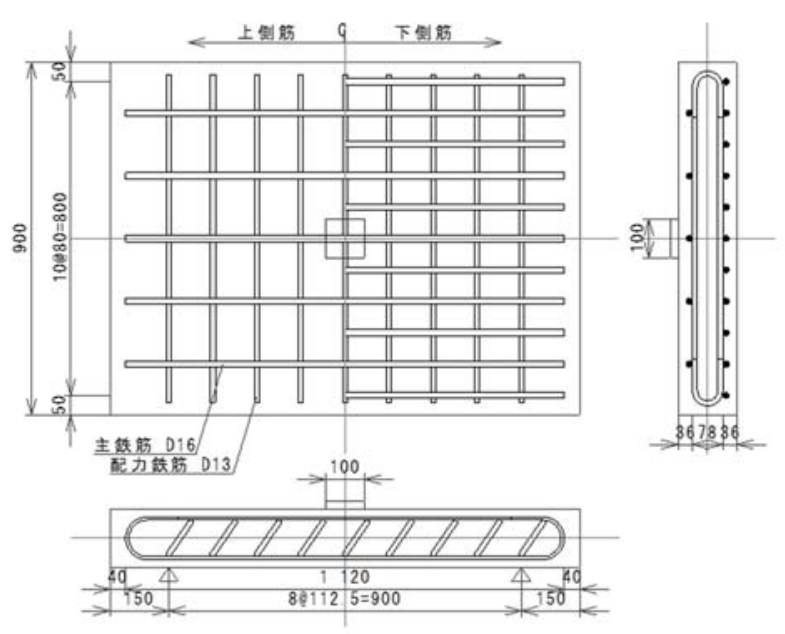

(b) No.7-10

Figure 1: Dimensions and bar arrangement of RC slab specimen

while non-reactive fine aggregates were mixed. $9.5 \mathrm{~kg} / \mathrm{m}^{3} \mathrm{Na}_{2} \mathrm{O}_{\text {eq }}$ of sodium chloride was dosed as an accelerator of the reaction. ASR specimens were cured in the sealed condition for 43 days for its enough hardening. Then, ASR specimens were put in a saturated salt water bath being warmed at 50 degrees Celsius to accelerate ASR reaction for about 1 year.

Figure 1 shows the dimensions and the bar arrangements of RC-slab specimens. D16 reinforcing bars $\left(f_{y}=367 \mathrm{~N} / \mathrm{mm}^{2}\right)$ were arranged in the longitudinal direction, while D10 $\left(f_{y}=393 \mathrm{~N} / \mathrm{mm}^{2}\right)$ or D13 reinforcing bars were placed in the transverse one. Test parameters were expansion strains due to $\operatorname{ASR}(0,2000$, $4000,6400 \mu$ ), loading types (static or fatigue), wet conditions during the loading test (wet or dry) and bar arrangements (single or double 
layer).

\section{EXPANSION DUE TO ASR}

The expansive strain of RC-slab specimens was mechanically measured on the top surface by measuring the relative distance (initial gauge distance is about $1,000 \mathrm{~mm}$ ) with large Vernier (Figure 2). Reinforcement strain was also measured by strain gauges. Figure 3 shows the measured expansive strain of prism specimens and RC-slab specimens with single bar layer. The expansive strain increased rapidly just after putting into water bath, which is 43 days after casting.

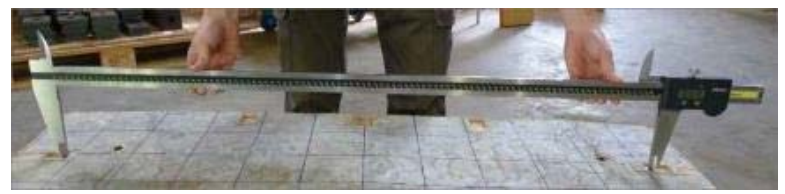

Figure 2: Measurement of expansion with Vernier

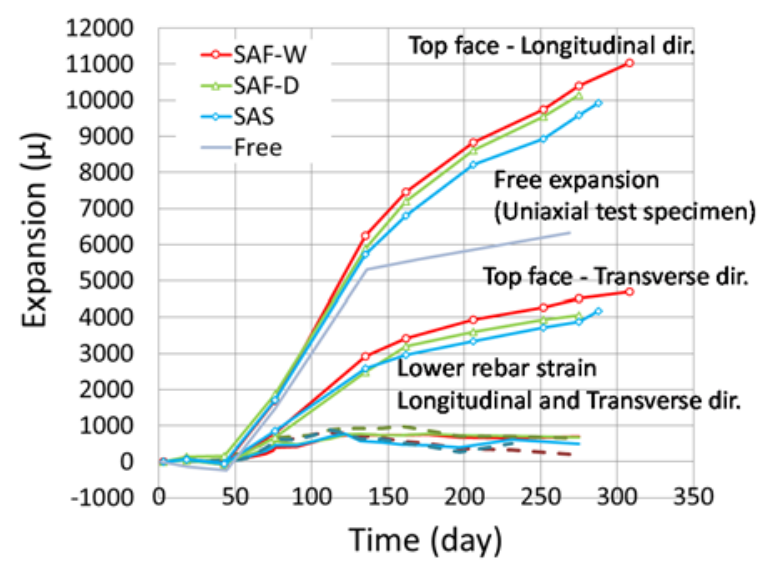

Figure 3: Expansive strain of specimen No.2, 4, 5

(Single layer)

The free expansion of the prism specimen reached up to $6400 \mu$ at 280 days. While the top surface strains were higher than the free expansion, reinforcement strains were significantly small due to the restraint effect in the case of the single layer bar arrangement. Owing to the differential strain towards the cross section, RC-slab specimens has bent shapes as shown in Figure 4. The center span deflection measured before the loading test was about $10 \mathrm{~mm}$ in the longitudinal direction for the single layer bar arrangement (Figure 5).

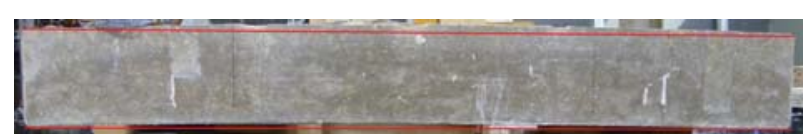

Figure 4: Side view after ASR expansion (SAS)

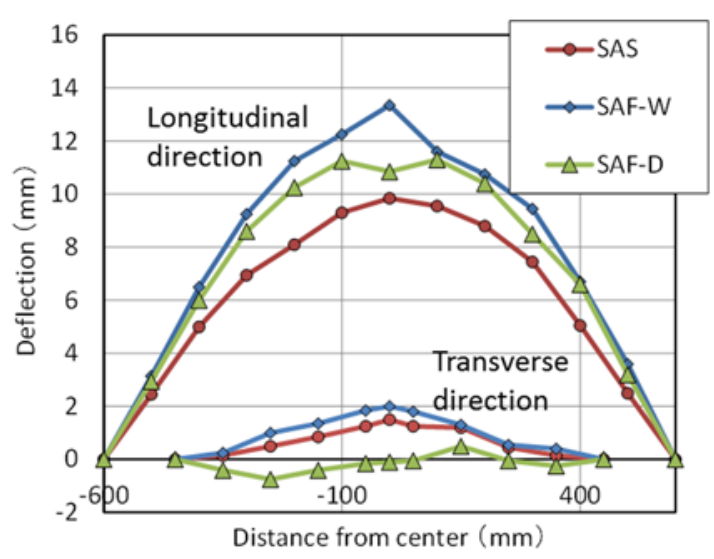

Figure 5: Deformation of specimen No.2, 4, 5 (Single layer)

On the other hand, clear deflection was not observed in the double layer bar arrangement case. Measured deflection was less than $1 \mathrm{~mm}$. As shown in Figure 6, the expansive strain on the top face was small due to restrictions of upper reinforcements.

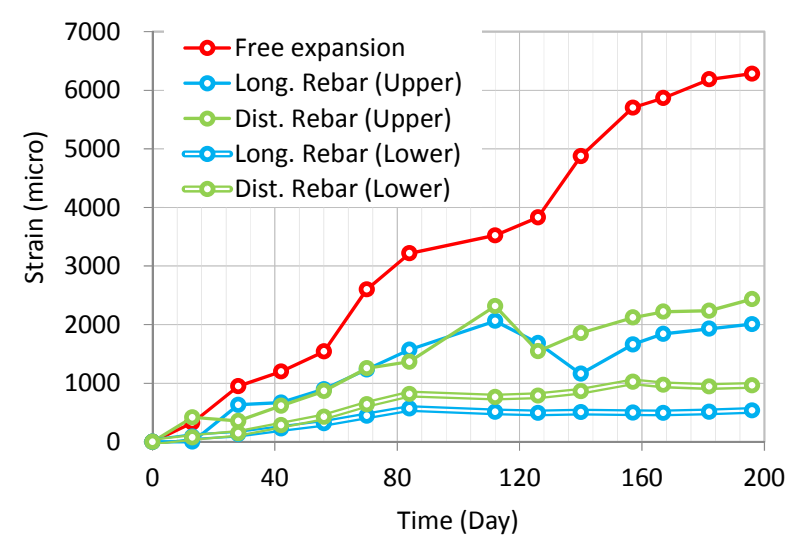

Figure 6: Expansive strain of specimen No.10 (Double layer)

Figure 7 and Figure 8 show the crack patterns of ASR specimens. While many lattice-like cracks were induced on the top faces, several longitudinal cracks were observed on the lower faces regardless of the bar arrangement. Because lower parts were strongly restrained by longitudinal bars, orthogonal cracks were not induced in lower faces. 


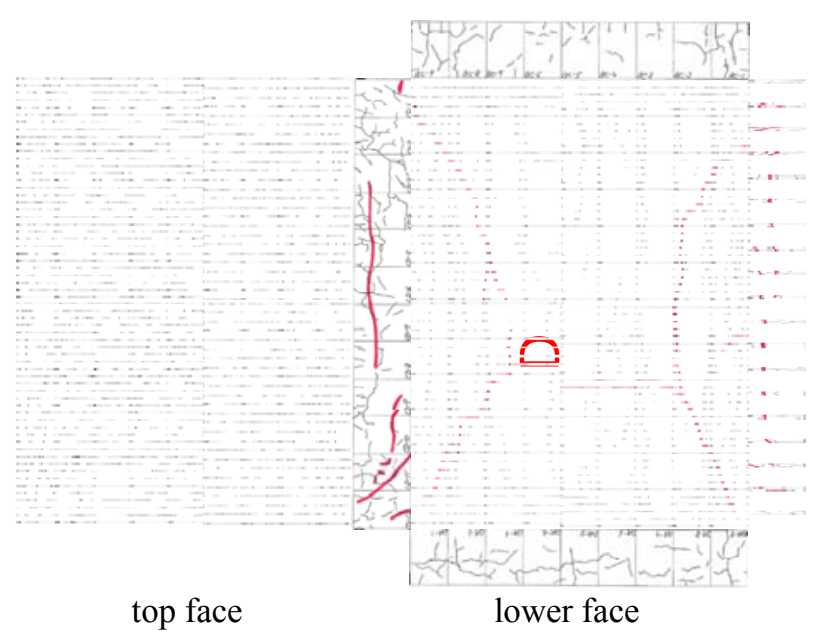

Figure 7: Crack patterns of SAS specimen (Red: Loading crack, Black: ASR crack)

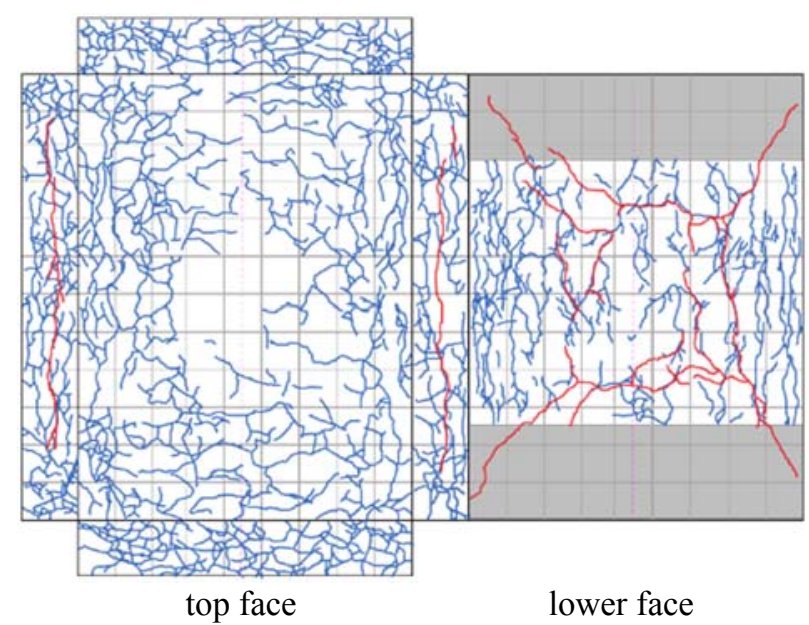

Figure 8: Crack patterns of DAS-6 specimen (Red: Loading crack, Blue: ASR crack)

\section{COMPRESSION TEST}

Uniaxial compression tests were carried out periodically to estimate the material properties of ASR concrete. In addition to the cylindrical specimens, concrete core specimens were picked from the RC blocks (Figure 9) to investigate the influence of reinforcement restraints on the material properties. Figure 10 and Figure 11 show the transitions of the elastic modulus and the compressive strength. Both elastic modulus and compressive strength were significantly reduced in accordance with ASR progress. Even expansion is restricted by the steel plates, both compressive strength and elastic modulus were reduced similar to the specimens in free expansion.

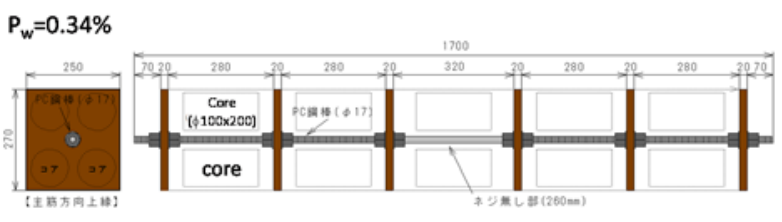

$P_{w}=0.85 \%$

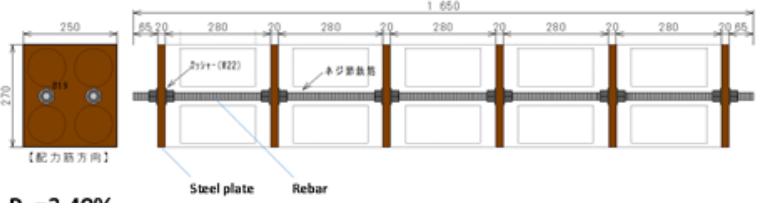

$P_{w}=3.40 \%$

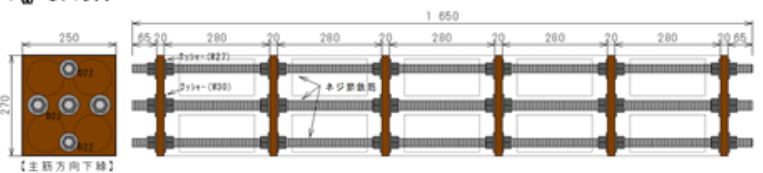

Figure 9: Bar arrangement of RC block to take concrete cores

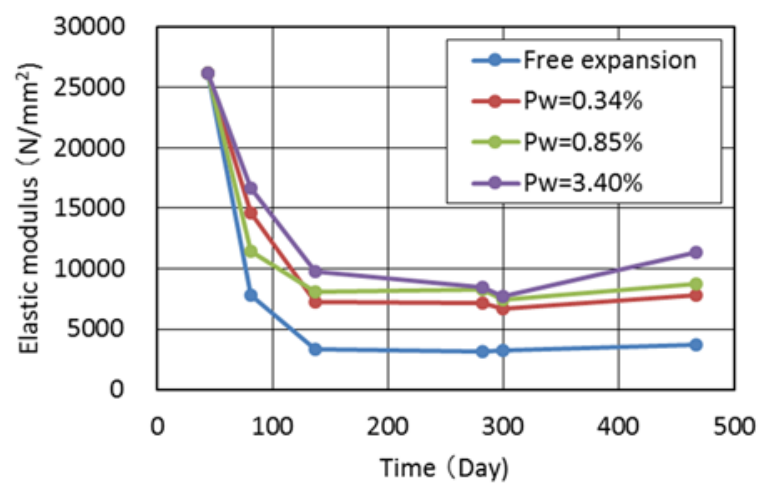

Figure 10: Transition of elastic modulus of ASR concrete (No.2-5)

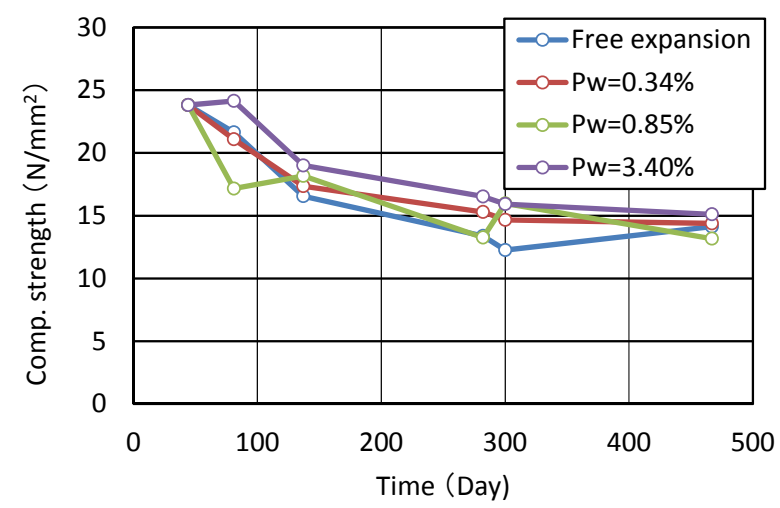

Figure 11: Transition of compressive strength of ASR concrete (No.2-5)

\section{STATIC PUNCHING SHEAR TEST}

The static punching shear tests were carried out with the fixed-point load. Specimens were simply supported with $1,200 \mathrm{~mm}$ span and loaded by $100 \mathrm{~mm}$ length - square steel plate. 
Loading test results of the single layer case are presented in Figure 12. ASR specimen had smaller punching shear strength than the sound one. Because the compressive strength of ASR concrete before ASR reaction starts $\left(24 \mathrm{~N} / \mathrm{mm}^{2}\right)$ was smaller than that of the sound concrete (41 $\mathrm{N} / \mathrm{mm}^{2}$ ), the test result of the sound specimen is corrected by JSCE design equation [2] as,

$$
V_{p c d} \propto \sqrt{f_{c d}^{\prime}}
$$

where, $V_{p c d}$ is the punching shear strength and $f^{\prime}{ }_{c d}$ is the compressive strength of concrete.

Even if the test result is corrected, conclusion is fixed, i.e., ASR reduces the static punching shear capacity in case of the single layer bar arrangement.

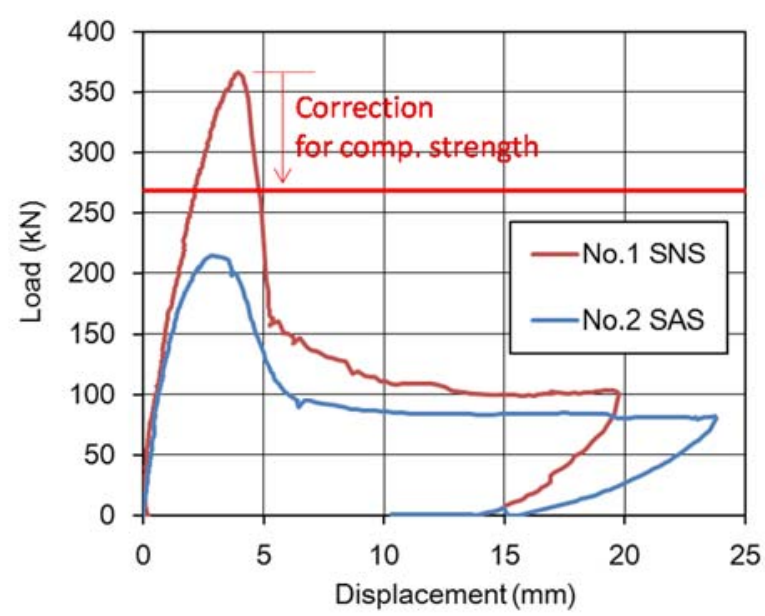

Figure 12: Load - center displacement relationship in static punching shear test (No.1-2)

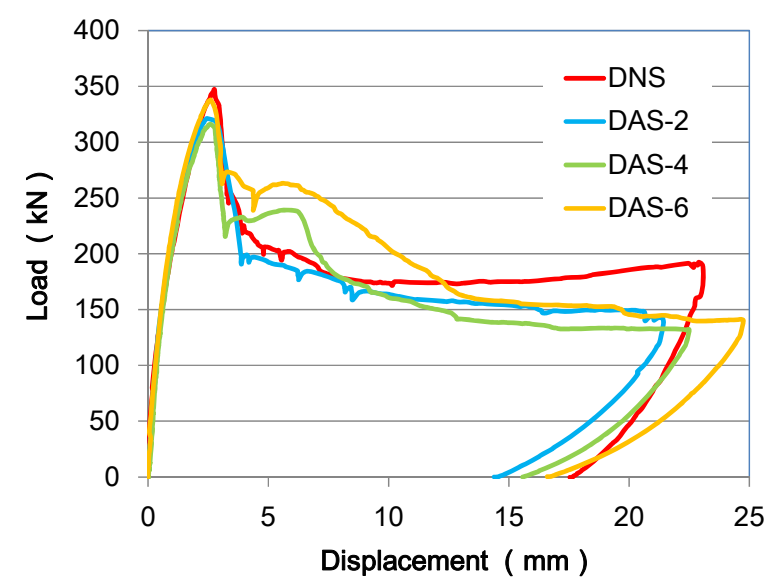

Figure 13: Load - center displacement relationship in static punching shear test (No.7-10)

In addition to the deterioration of material properties such as the compressive strength, pre-strain due to ASR expansion would reduce the punching shear capacity. As shown in Figure 3, the expansions in the upper part of the slab specimen were larger than the free expansion. This behavior means that the tensile strain was induced in the upper part of slabs. Because the initial stiffness was not reduced in the ASR specimen, material properties of the slab specimen should be different from the element test as shown in Figures 10-11.

Meanwhile, ASR did not affect the punching shear capacity so much in the case of the double layer as shown in Figure 13.

As concrete was pre-stressed through the upper and the lower reinforcement, capacity decrement due to deterioration of materials would be canceled by strength enhancing effect with pre-stress force.

\section{FATIGUE LOADING TEST}

The fatigue test was carried out in the single layer case. The sound and ASR specimens were loaded in air dry or wet condition. In case of the wet state, tap water was supplied on the top face. The $80 \%$ of the static punching shear capacity was repeatedly applied.

Figure 14 shows the results in terms of S-N diagram. Failure cycles of the sound specimens were 3,039 in the dry condition and 1,079 in wet case, respectively. These numbers coincide with the estimated fatigue failure cycles by JSCE design equation [2].

$$
V_{r p d}=V_{p c d}\left(1-\frac{V_{p d}}{V_{p c d}}\right)\left(1-\frac{\log N}{14}\right)
$$

where, $V_{r p d}$ : the fatigue strength, $V_{p c d}$ : static puncing shear strength, $V_{p d}$ : dead load, $N$ : number of cycles. The static punching shear strength is calculated by Maeda and Matsui model [3] as follows.

$$
\begin{aligned}
& V_{p c d}=\tau_{s \max } \cdot A_{s}+(1 / 2) \cdot \sigma_{t \max } \cdot A_{d} \\
& \tau_{s \max }=0.251 f_{c}^{\prime}-0.00251 f^{\prime}{ }_{c}^{2} \\
& \sigma_{\text {tmax }}=0.269 f_{c}^{\prime 2 / 3}
\end{aligned}
$$

where, $\tau_{\text {smax }}$ : the shear strength of concrete, $A_{s}$ : the effective area for shear transfer, $\sigma_{\text {tmax: }}$ the dowel action stress, $A_{d}$ : the effective area for dowel action. 


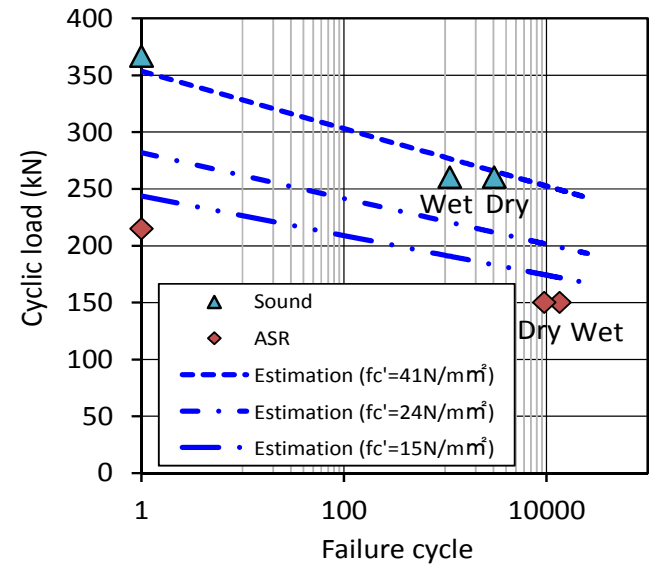

Figure 14: S-N diagram (No.1-6)

Even though the compressive strength measured by the free expansion cylinder is used in Eq. (3), the estimated strength is higher than the experiment. Reduction of the punching shear capacity cannot be explained solely by the reduced strength of concrete. It is well known that water supply causes reduced fatigue capacity of RC slabs [1]. However, the ASR slab specimen was not weakened under the wet condition.

\section{INTERNAL CRACK OBSERVATION}

After the loading test, specimens were sawn in the longitudinal and transverse directions to observe the internal cracks. Figure 15 shows the cross sections of the single bar layer specimens in the longitudinal direction. In the sound cases, punching shear cracks are propagated from the loading point to the bottom face as straight as a line ((a), (b), (c) in Figure 15).

On the other hands, punching shear cracks propagated along longitudinal bars for ASR specimens ((d), (e), (f) in Figure 15). This is because many horizontal cracks were initially induced by ASR expansion. This trend is more clearly observed in case of double bar layers (See Figure 16).

\section{COMPUTATIONAL MODEL}

Fluid actions and migration of silica gels through cracked concrete media matrix can be considered by using two-phase and poromechanics approach $[4,5]$. The original

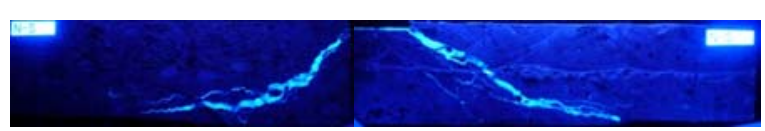

(a) Sound (SNS)

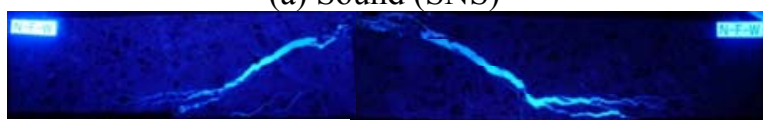

(b) Sound fatigue in wet condition (SNF-W)

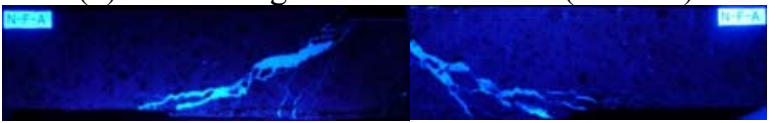

(c) Sound fatigue in dry condition (SNF-D)

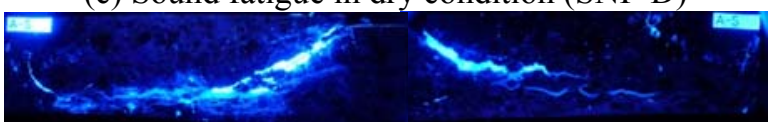

(d) ASR static (SAS)

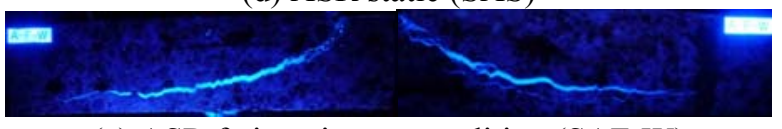

(e) ASR fatigue in wet condition (SAF-W)

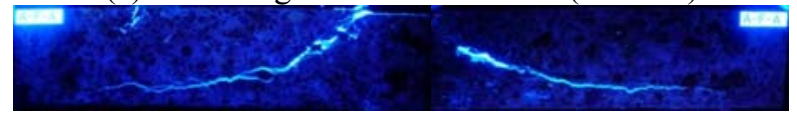

(f) ASR fatigue in dry condition (SAF-D)

Figure 15: Cross sectional cracks in longitudinal direction (Single bar layer)

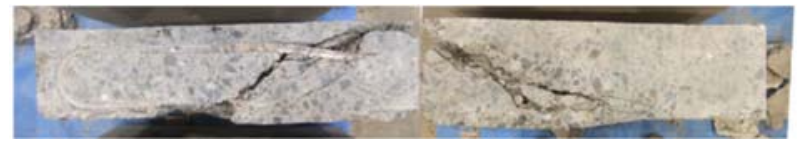

(a) Sound (DNS)

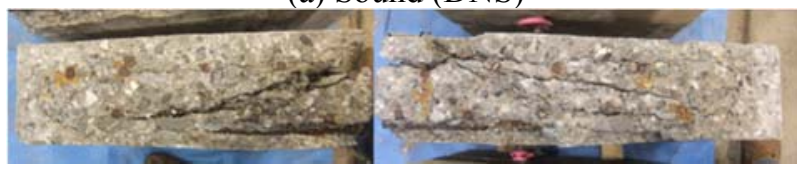

(b) ASR (DAS-6)

Figure 16: Cross sectional cracks in longitudinal direction (Double bar layers)

governing equation for isotropic soil-pore system is described as,

$$
\sigma_{i j}=\sigma_{i j}^{*}+\delta_{i j} p
$$

where, $\sigma_{i j}$ is the total stress, $\sigma^{*} i j$ is the effective stress and $p$ is pore pressure. The effective stress of the skelton phase is calculated from the constitutive laws for concrete [6]. To calculate the pore pressure, the substantial linear stiffness is assumed as,

$$
\begin{aligned}
& p=\overline{K_{f}}\left(w_{i i}+\varepsilon_{i i}\right) \\
& \overline{K_{f}}=\left(\frac{1-n}{K_{c}}+\frac{n}{K_{g}}\right)
\end{aligned}
$$

where, $K_{c}$ and $K_{g}$ are the bulk stiffness of concrete matrix and the produced silica gel, $w_{i i}+\varepsilon_{i i}$ is the volumetric strain of the gel inside 
cracked concrete and $n$ is constant to represent the effect of porosity. Darcy law is used to consider the flow of liquid phase of the gels. The permeability of ASR gel in capillary pores $\kappa^{*}$ is assumed as $10^{-20} \mathrm{~m} / \mathrm{s}$ [7][8], which is significantly smaller than the pure condensed water $\left(10^{-7} \mathrm{~m} / \mathrm{s}\right)$. In cracked concrete, the authors apply for anisotropy by assuming that pore pressure acts normal to the crack plane as,

$$
\sigma_{i j}=\sigma_{i j}^{*}+\delta_{i j} l_{i} p
$$

where, $l_{i}$ is the unit directional vector normal to crack plane (Figure 17). The permeability of cracked concrete is estimated as,

$$
\kappa_{i}=\kappa^{*}\left\{1+\left(\frac{\varepsilon_{j j}+\varepsilon_{k k}}{a}\right)^{2}\right\}
$$

where, $\varepsilon_{j j}+\varepsilon_{k k}$ is the transverse in-plane strain. The value denoted by " $a$ " is the material constant where $1.0 \mathrm{E}^{-4}$ is tentatively assumed.

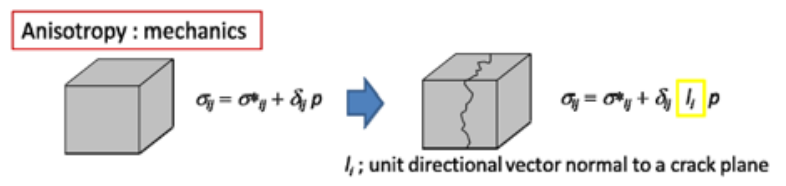

Figure 17: Anisotropy of cracked concrete

\section{ANALYSIS OF STATIC TEST}

As the model deals with migration of the gel inside micro pores of concrete matrix, the expansive strain of cement matrix reduces spontaneously provided that the expansive deformation is restricted by reinforcement or external forces. Consequently, differential expansive strain deforms the slab specimen as shown in Figure 18 for the single layer case.

Figure 19 shows the relation of the free expansion and the center deflection. Numerical results coincide with the experiments with both single and double layer cases. The restriction by the upper reinforcement brings about significant reduction of deformation in the analysis as well.

Figure 20 summarizes numerical results of static punching shear strength of single layer case. Numerically estimated maximum load decreases in accordance with the expansive reaction. And predicted loads follow the experimental results.

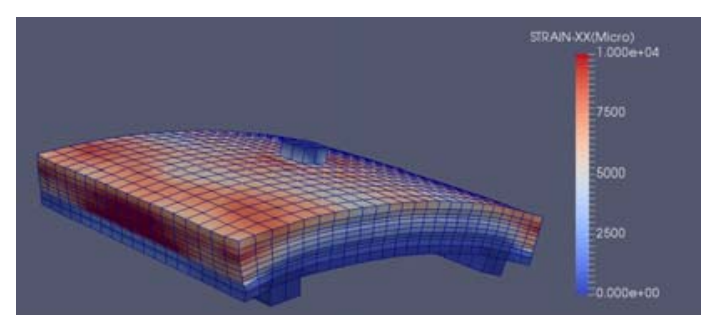

Figure 18: Deformation due to ASR (SAS specimen)

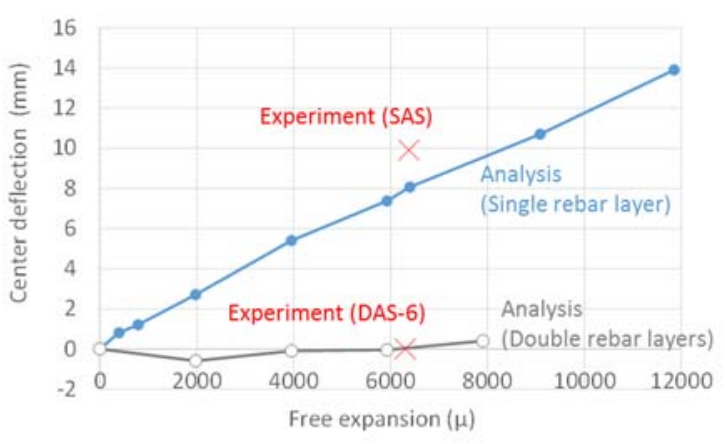

Figure 19: Deformation due to ASR expansion

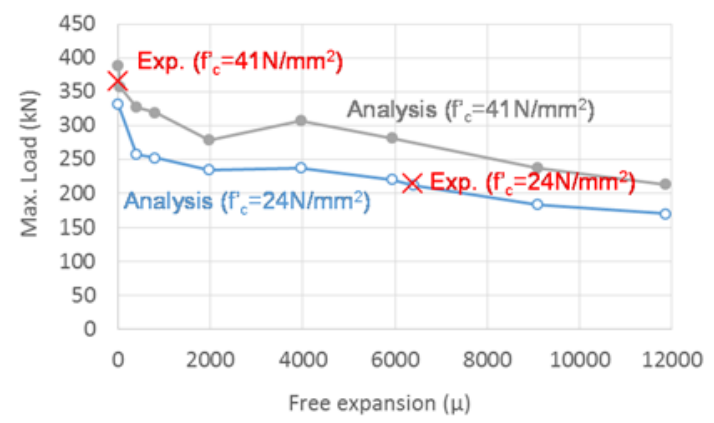

Figure 20: Free expansion VS punching shear strength (Single layer)

Although the analysis succeeds to simulate the punching shear capacity of ASR specimens, the stiffness of ASR specimens is predicted being smaller (Figure 21), because the skeleton stiffness is numerically reduced by cracking. But in fact, the stiffness of ASR damaged slab specimens is almost similar to the sound one (Figures 12 and 13) even though much cracking develops. Figure 22 shows numerical results of the case of double layered reinforcement. Smaller stiffness and capacity are predicted for ASR. But, the substantial reduction is not observed in the experiment (Figure 13). This multi-directional cracking and its structural stiffness are left to be investigated in future study. 


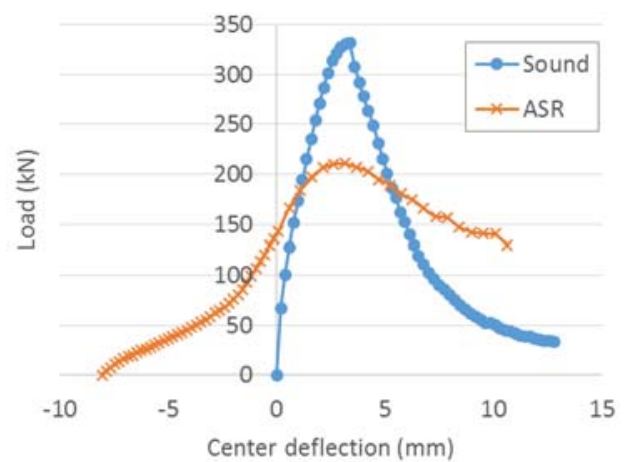

Figure 21: Load-deflection of the single layer case

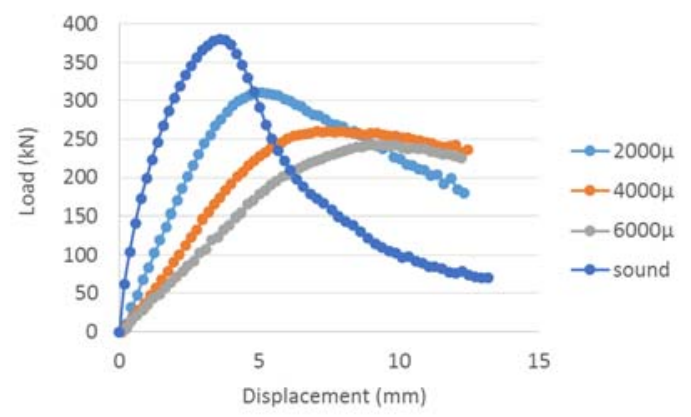

Figure 22: Load-deflection of the double layer

\section{FATIGUE ANALYSIS}

Figure 23 shows Numerical results of cyclic punching shear test in S-N diagram. Sensitivity of cyclic load coincides with experimental results both in sound case and ASR case. However ASR specimen has smaller fatigue strength, slope of $\mathrm{S}-\mathrm{N}$ curve is milder than sound specimen.

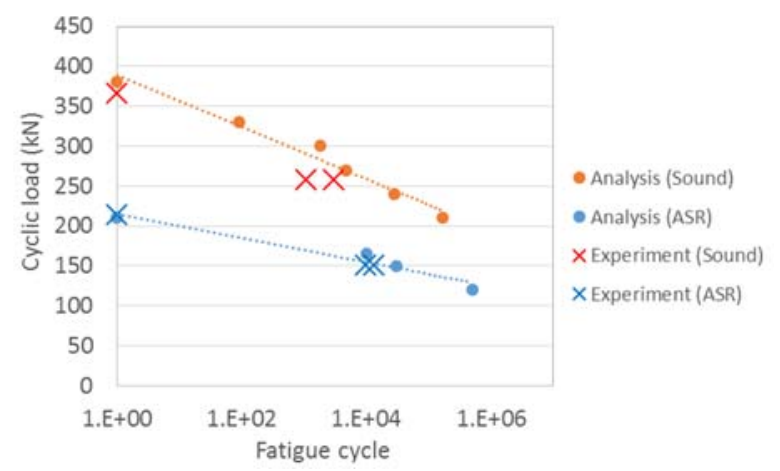

Figure 23: S-N diagram of cyclic punching shear loading test (Single layer)

\section{CONCLUSIONS}

It is experimentally clarified that the punching shear capacity of ASR slabs depends on steel bar's arrangement. Poro-mechanics based ASR model may simulate the static capacity of ASR slabs according to the anisotropy and the amount of reinforcement arrangement. The stiffness of ASR slabs with cracking of concrete is simulated being smaller than the reality. This point is left for future study.

\section{ACKNOWLEDGEMENT}

This study was financially supported by Council for Science, Technology and Innovation, "Cross-ministerial Strategic Innovation Promotion Program (SIP), Infrastructure Maintenance, Renovation, and Management" granted by JST.

\section{REFERENCES}

[1] Matsui, S. 1987. Fatigue strength of RC slabs of highway bridge by wheel running machine and influence of water on fatigue, Proc. of JCI, 9(2), 627-632.

[2] JSCE Standard Specification for concrete structures, Design, 2013.

[3] Maeda, Y. and Matsui, S. 1984. Punching shear load equation of reinforced concrete slabs, Proc. of JSCE, 348, V-1, 133-141.

[4] Maekawa, K. and Fujiyama, C. 2013. Ratedependent model of structural concrete incorporating kinematics of ambient water subjected to high-cycle loads. Engineering computations, 30(6), 825-841.

[5] M. Biot. 1941. General theory of threedimensional consolidation, J. Applied Physics, Vol.12, No.2, pp.155-164.

[6] Maekawa, K., Pimanmas, A. and Okamura, H. 2003. Nonlinear Mechanics of Reinforced Concrete, Spon press.

[7] Takahashi, Y., Tanaka, Y. and Maekawa, K. 2015. Chemo-hygral model for ASR expansion and its effects on fatigue lives of bridge slabs. Proc. of 13th Int. Conf. on Computational Plasticity, 944-955.

[8] Takahashi, Y., Shibata, K., Maruno, M. and Maekawa, K. 2015. Uniaxial restraint tests under high-stress conditions and a chemohygral model for ASR expansion, CONCREEP 10, 1061-1065. 